\title{
Os efeitos das pastagens sobre a fertilidade do solo na Amazônia Brasileira: consequências para a sustentabilidade de produçào bovina
}

\author{
Philip M. Fearnside (")
}

\begin{abstract}
Resumo
A floresta pluvial amazônica está sendo rapidamente substituída por pastagens de gado na medida em que os investidores respondem aos incentivos financeiros $e$ ao atrativo cias novas estradas de rodagem. $O$ incentivo do governo brasileiro para pastagens está ligado às declaraçōes cie que a pastagem promove a fertilidade do solo e portanto representa um meio "racional" de desenvolvimento na Amazônia. O exame das mudanças de fertilidade do solo pōe em dúvida tanto as declarações de promoçăo de fertilidade do ponto de vista de crescimento da pastagem, quanto a pressuposição de produçōes indefinidamente sustentáveis de gado de corte.
\end{abstract}

\section{INTRODUÇÃo}

A conversão rápida das florestas tropicais pluviais da Amazônia brasileira em pastagem de gado de corte está sendo feita tanto pelos gigantes internacionais como Volkswagen, King Ranch, e Armour-Swift, como pelas centenas de investadores brasileiros que estão sendo atraídos das áreas urbanas do Sul do Brasil, para estabelecerem fazendas na Amazônia. As fazendas de gado estão sendo incentivadas através de um programa altamente prioritário de incentivos fiscais e de financiamento com juros baixos, com o objetivo declarado de "transformar este setor em um dos mais dinâmicos da economia regional" (SUDAM-BASA, 1972: 29) .

A construção ainda em andamento de uma vasta rede de estradas de rodagem em toda parte da Amazônia brasileira tem facilitado a rápida expansão das fazendas de gado (Fig. 1). Estas vastas áreas são derrubadas, queimadas e, em todos com exceção das fazendas menores, são plantadas diretamente com pastagem sem um período intermediário de uso em outras culturas (Fig. 2). Operações maiores semeiam sementes de capim por meio de aviões, sendo que a escolha mais comum é o capim colonião (Panicum maximum).

$\mathrm{O}$ bom senso da corrida em voga para converter a floresta pluvial em pastagem pode, e deve, ser debatido por várias razões. No Brasil, o foco prevalescente deste debate é a questão de como as pastagens de gado afetam a fertilidade do solo na região. Embora, nem sempre observada pelos participantes desta controvérsia, a manutenção da fertilidade do solo somente é importante como uma parte de uma questão mais ampla, ou seja, se o rendimento poderá ser sustentável, como é antecipado pelos planejadores brasileiros. A maior parte deste debate se refere ao uso das vastas áreas de terra firme que são cobertas de floresta alta, em vez das áreas mais limitadas de várzea, os campos "naturais", e aquelas áreas de cerrado que são incluídas na Amazônia Legal. A discussão seguinte, da controvérsia sobre fertilidade do solo sob pastagem, se refere às áreas de terra firme amazônica sob floresta alta (Fearnside, 1980).

\section{A CONTROVÉRSIA SOBRE FERTILIDADE DO SOLO SOB PASTAGEM}

Uma opiniăo que tem sido expressa repetidamente nas reuniões científicas em toda parte da América Latina, nos anos recentes, é a de que a plantação de pastagens mcihora a qualidade do solo. Falesi (1974) descobriu o seguinte, quando os solos sob floresta virgem foram comparados com os solos sob pastagens de várias idiades tanto ao longo da Rodovia Belém-Brasília, próximo a Paragominas, no Pará, como no nordeste de Mato Grosso :

Logo após a queimada (da floresta) a acidez é neutralizada, com mudança de $\mathrm{pH}$ de 4 para acima

(*) - Instituto Nacional de Pesquisas da Amazônia, Manaus. 


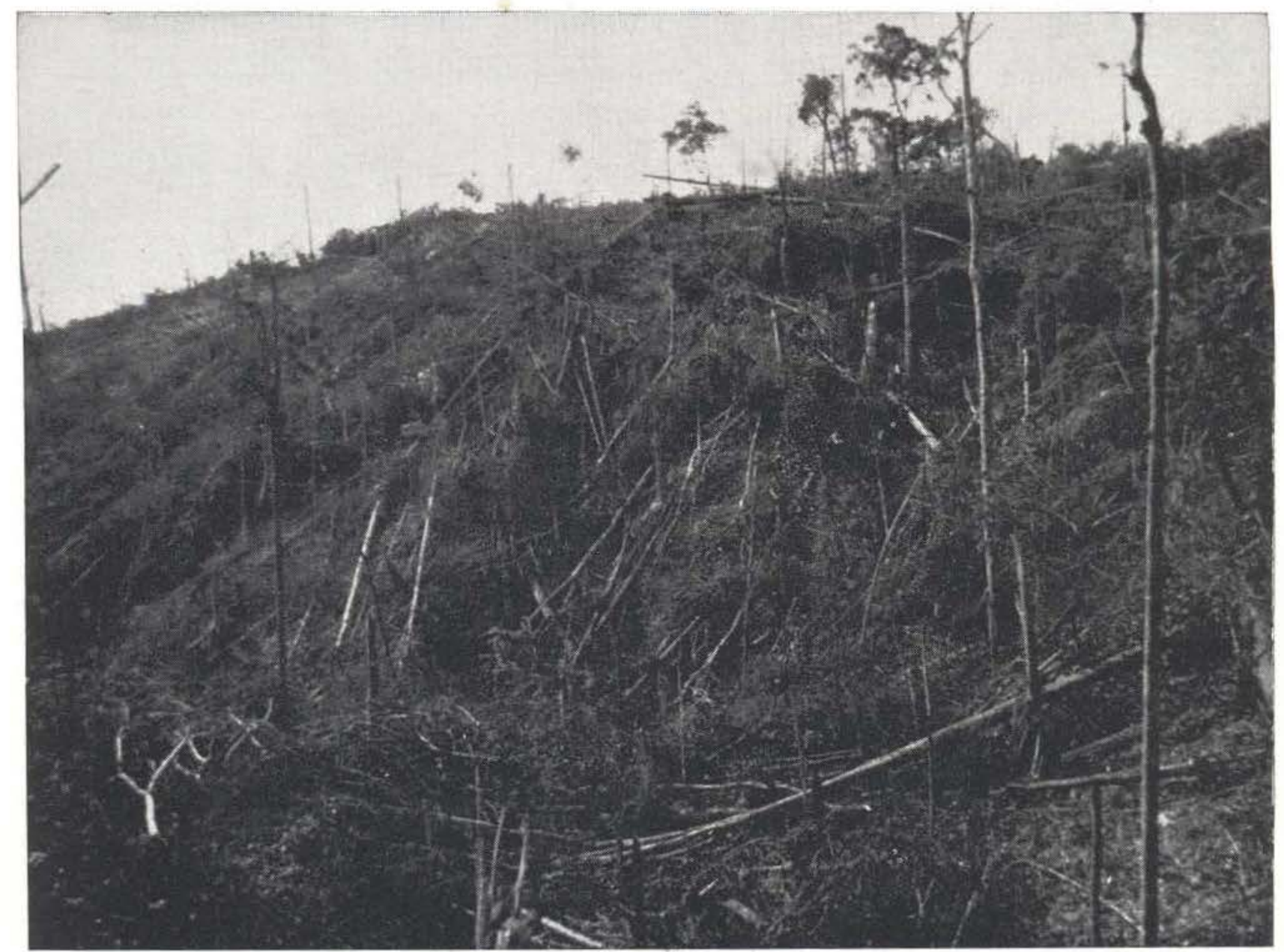

Fig. 1 - Grandes fazendas, tais como esta na Rodovia Paragominas-Tomé-Açu, derrubam a floresta pluvial tão rapidamente quanto os recursos financeiros permitem.

de 6 e o alumínio desaparecendo, persistindo esta situação nas diversas idades de pastos, tendo a pastagem mais velha a idade de 15 anos, localizada em Paragominas.

Os elementos nutrientes tais como cálcio, magnésio e potássio elevam-se na composiçăo química do solo, e permanecem estáveis no decorrer dos anos. O nitrogênio baixa logo após a queimada mas, no entanto, em poucos anos volta a apresentar o teor semelhante ao existente na mata primitiva. (Falesi, 1974)

Isto é seguido pela conclusão de que :

A formação de pastagens em latossolos e podzó. licos de baixa fertilidade é uma maneira racional e econômica de ocupar e valorizar essas extensas árees. (Falesi, 1974)

O Dr. P. de T. Alvim, diretor da Comissão Executiva do Plano da lavoura Cacaueira, disse aos participantes da reunião do Projeto Ho- mem no Biosfera, das Nações Unidas, realizada no Rio de Janeiro em 1974 que "Um Iongo período de repouso sob pastagem de Panicum maximum renovará o conteúdo de fósforo, cálcio e nitrogênio do solo da floresta tropical" (Lawton, 1974). Cơm exceção da alegação quanto ao fósforo, isto provavelmente se refere aos resultados preliminares do estudo de Falesi $(1974,1976)$.

A noção de pastagem beneficiando o solo foi levada adiante em recomendações oficiais para o uso da terra. Em um relatório de 1974. da Empresa Brasileira de Pesquisa Agropecuária - Instituto de Pesquisa Agropecuária do Norte (EMBRAPA-IPEAN, atualmente CPATU) fornecendo recomendações para 2 área de $10.686 \mathrm{~km}^{2}$ à qual se tem acesso pelo trecho de $1.760 \mathrm{~km}$ da Rodovia Transamazônica, si- 
tuado entre Itaituba e Rio Branco, a recomendação onipresente é :

... a formação de pastagens que, quando bem manejadas, recobrem totalmente a superficie dos solos, protegendo-os contra a erosão, ao mesmo tempo que restitui o equilibrio biológico (IPEAN, 1974).

A tendência das recomendações oficiais de uso da terra, não recomendando as culturas anuais e favorecendo a pastagem, pode ser observada nas diferenças de recomendações entre o levantamento sobre o trecho da Rodovia Transamazônica, Estreito-Itaituba, feito pela EMBRAPA-IPEAN, em 1972 (Falesi, 1972), e as recomendações de 1974, para os mesmos tipos de solo, no trecho Itaituba-Rio Branco. Em 1974, o Latossoio Amarelo (Oxisol) é re- comendado racionalmente .... para culturas perenes, reflorestamento e pastagens (IFEAN, 1974) com a observação de que é anti-econômico adubar culturas anuais. Em 1972, as mesmas observações, relativas a culturas perenes, reflorestamento e pastagens, são feitas juntamente com a impraticabilidade de adubação, mas a esperança para culturas anuais é apresentada através da citação de ensaios de variedades da EMBRAPA-IPEAN (Kass \& Lopes, 1972) que são descritas como demonstrativas de "alta produtividade, usando como solo năo somente o Latossolo Amarelo textura muito pesada, mas também de textura média, cbtendo bons resultados experimentais, sem emprego de adubos e corretivos" (Falesi, 1972).

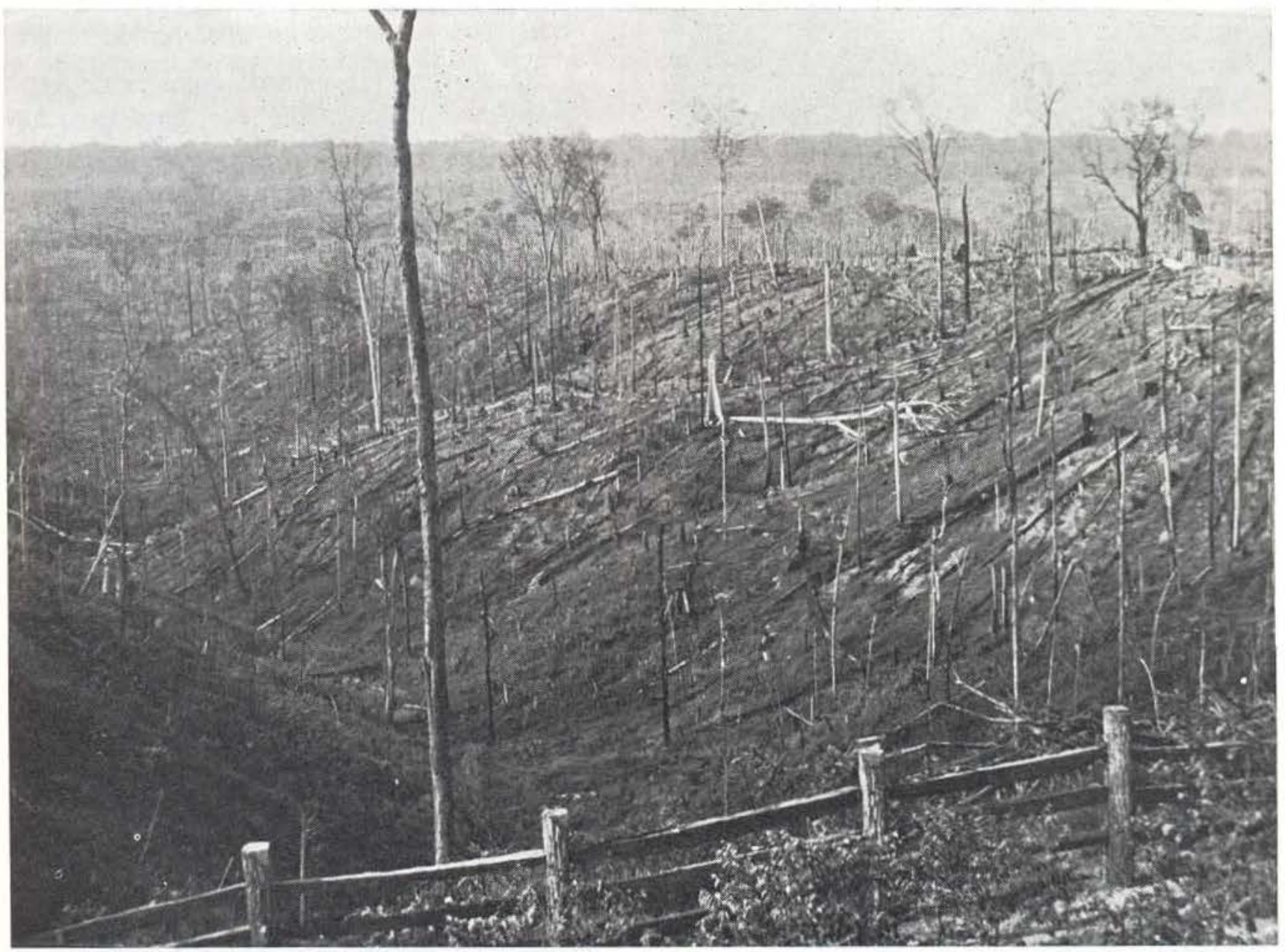

Fig. 2 - As grandes fazendas plantam o pasto logo após a derrubada. 0 crescimento inicial da pastagem é melhor do que nos anos posteriores face à fertilidade do solo mals alta e à competiçâo reduzida com ervas daninhas invasoras. 
A crença de que a pastagem melhora o solo caminha lado a lado com a recomendação oficial de que solos pobres devem ser usados como pastagens. Nas recomendações de 1974 da EMBRAPA-IPEAN para o trecho Itaituiva-Rio Branco da Rodovia Transamazônica, a pastagem é aconselhada como um uso racional da terra para todos os solos encontrados, com exceção de duas pequenas áreas: uma, um tipo de Podzólico-Vermelho Amarelo (Ultisol) com cascalhos (IPEAN, 1974). e, o outro, um setor de "Solos Hidromórficos Indiscriminados" com problemas de drenagem (IPEAN, 1974). Todos os outros solos são recomendados para pastagem, incluindo mesmo um, "Laterita Hidromórfica", com drenagem "moderada". Sem querer entrar na discussão dos apelos, muitas vezes exagerados, do perigo da formação de laterita (píintita), a descrição desta unidade de solo ilustra a conseqüência lógica da premissa de que solos pobres podem ser melhorados por meio da influência benéfica de uso sob pastagem. Este solo é descrito como possuidor de uma "característica intrín sica":

... a partir do horizonte $\mathrm{B}_{21} \mathrm{p}_{1}$, o "plinthite", que é um material fortemente intemperizado, com elevado teor de sexquióxidos de ferro e alumínio, rico em argila e pobre em húmus, tendo :rreversivelmente para "hardpan". (IPEAN, 1974)

A recomendação de que o solo Laterita Hidromórfica seja usado para pastagem, é moderada, com a qualificação de que seja obedecendo entretanto a uma orientação técnica racional no que diz respeito à formação de pastagens com espécies adaptáveis às condições locais (IPEAN, 1974).

O Projeto RADAM tem classificado o uso potencial da terra para o Quadrângulo Belém que inclui o trecho Altamira-Itaituba da Rodovia Transamazônica. Toda a área do Quadrângulo Belém é considerada apropriada para fazendas de gado, embora esta recomendação predomine nas classes mais baixas de uso potencial de terra (Departamento Nacional de Produção Mineral, Projeto RADAM, 1974: V/14 e $V / 23)$.

$\mathrm{O}$ crescimento rápido da quantidade de pastagem em tơda a Amazônia torna urgente a determinação dos efeitos da pastagem sobre o solo da região.

\section{MUdANÇAS DO SOLO SOB PASTAGEM}

O conhecimento das mudanças de solo sob pastagens tropicais está longe de ser suficiente. Existe um número de razões em virtude das quais o apelo de aumento da fertilidacie do solo sob pastagem deve ser considerado como distante da confirmação como declaração geral sobre os solos sob pastagem tropical. Embora os resultados sobre o solo obtidos no estudo na Belém-Brasília (Falesi, 1974, 1976) possam ser a conseqüência de um verdadeiro melhoramento na qualidade do solo face às diferenças no tempo gasto sob pastagens, eles também podem ser um resultado da variabilidade natural entre os locais de onde as amostras de solo foram colhidas. Precisa-se de mais estudos, especialmente pesquisas baseadas em amostragem repetida dos mesmos locais sob pastagem, no decorrer de tempo.

O pequeno tamanho da amostra do estudo da Belém-Brasilia pode ser uma explicação para os resultados obtidos. Os dados do solo para um estudo da capacidade de suporte numana na Rodovia Transamazônica (Fearnside, 1978) têm mostrado repetidamente a necessidade de amostras grandes para poder penetrar o efeito mascarador das diferenças fortuitas entre os locais em comparação, de forma que os efeitos dos tratamentos possam ser determinados. No estudo da Rodovia Transamazônica foram feitas 1.000 comparações entre pares de amostras de solo, 642 das quais foram comparações entre locais "usados" e virgens adjacentes. Locais "virgens" referem-se a locais não usados anteriormente por colonos, embora populações indígenas ocupassem todas estas áreas durante séculos antes da chegada recente de rodovias. A maior parte das comparações não envolvem pastagem. A necessidade de tamanhos de amostras grandes tem sido amplamente confirmada nas diversas análises feitas usando este conjunto de dados (Fearnside, 1978) .

O estudo dos solos na Rodovia Transamazônica vem indicando a necessidade de grande cuidado na escolha dos pares "virgens" imediatamente adjacentes aos campos "usados". Freqüentemente, no estudo da Rodovia Transamazônica, diferenças, facilmente observáveis na aparência dos solos pertencentes ao mes- 
mo lote de colono de 100 hectares, tornam necessária a obtenção de mais do que uma amostra "virgem" para comparação com roças em partes diferentes do lote. Mapas do solo mostram algumas destas variações de pequená escala na qualidade do solo (Fearnside, 1978j. Embora os reiatos do estudo da BelémBrasilia não forneçam pormenores de como os pares "virgens" foram selecionados, existem distâncias um tanto grandes entre pedaços de terra sob floresta virgem na área em torno de Paragominas, o que podem acrescentar uma variabilidade adicional às comparações com pastagens localizadas a uma certa distância dos locais das amostras "virgens" emparelhadas.

A aparência geral das pastagens próximas a Paragominas quando eu visitei a área em 1974, 1975 e 1976, desmentia os cartazes que denominaram Paragominas como "A Capital do Boi Gordo". Grandes extensões de pastagem, revertendo a capoeira, podem ser facilmente observadas (veja Fig. 3). A invasão de ervas daninhas pode seguir o seu curso em pastagens tropicais como ou sem desgaste do solo, o que indica a necessidade de cuidado especial na interpretação das tendências acerca do solo, mesmo que no sentido do melhoramento, como indicadores da praticabilidade do usc contínuo como pastagem pelas numerosas fazendas novas na área amazônica do Brasil.

Exames dos resultados do solo, apresentados no relatório final do estudo da BelémBrasilia, revelam algumas indicações de que a produção de pastagem pode não ser tăo sustentável quanto a conclusão do relatório indicaria. A parte do problema de invasão de ervas daninhas, o qual o relatório menciona por alto (Falesi, 1976), as próprias mudanças do solo não são totalmente favoráveis às pastagens. Os dados do experimento de adubação da pastagem em Belém (Serrão et al., 1971), que foram analisados em outra publicação (Fearnside, 1979a), indicam que o fósforo é o elemento que melhor prediz a fertilidade do solo para produção de capim nas condições do experimento. $\mathrm{O} \mathrm{pH}$ e outros indicadores, para os quais os efeitos "benéficos" da pastagem foram achados, não são tão relevantes para produção da mesma. Os dados apresentados no relatório do estudo da Belém-Brasília

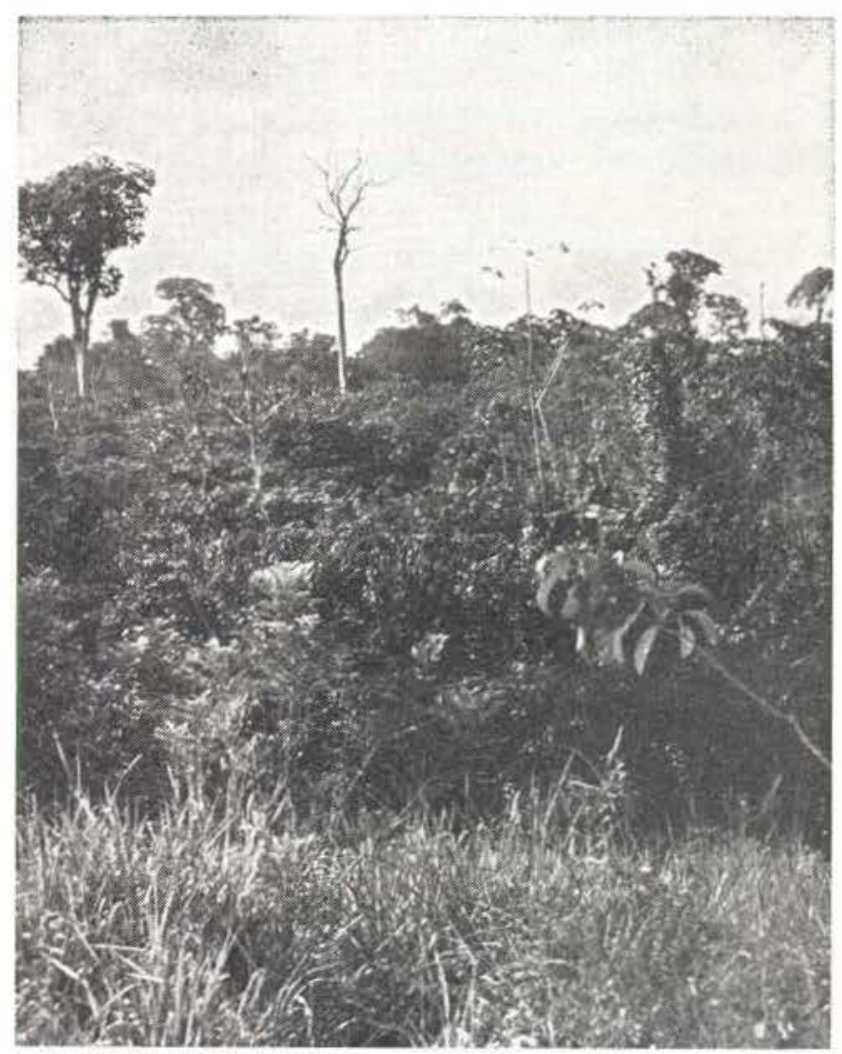

Fig. 3-Gastos com o controle de crescimento de capoeira podem ser anti-econômicos. Pastagens abandonadas, tais como esta perto de Paragominas, năo são raras.

para fósforo (Falesi, 1976), não obstante serem demonstrativos de alguma variabilidade, apresentam uma clara tendência decrescente do fósforo disponível depois do pico inicial, após a queimada da floresta virgem (Fig. 4) . $\mathrm{O}$ fósforo disponível $\left(\mathrm{P}_{2} \mathrm{O}_{5}\right)$ aumenta de 0,69 $\mathrm{mg} / 100 \mathrm{~g}$, na floresta virgem para $4,13 \mathrm{mg} / 100$ $\mathrm{g}$, na pastagem nova, o que pode sei atribuído à queimada da mata virgem ao invés do efeito da pastagem. A queimada da floresta é conhecida como de efeito marcante sobre o fósforo (Fearnside, 1978). Depois deste pico inicial, os nove pontos adicionais de dados no estudo da Belém-Brasília mostram um declínio definido, com apenas uma leve variação para um plano de valor mais baixo alcançado depois de cinco anos. O valor, depois de cinco anos, é $0.46 \mathrm{mg} / 100 \mathrm{~g}$ e permanece nesta imediaçăo até à idade máxima disponível quando ele é $0,46 \mathrm{mg} / 100 \mathrm{~g}$ no décimo ano. De menor importância do que o fato de que isto é inierior 
ao valor encontrado no solo da mata virgem, é o de que esta é uma ordem de grandeza inferior ao pico do fósforo alcançado depois da queimada. A sensibilidade da produção da pastagem aos niveis de fósforo significa que diminuiçōes deste magnitude sob pastagem acusarão um efeito negativo na produção da mesma no decorrer do tempo.

A interpretação dos resultados do estudo da Belém-Brasília é crucial, especialmente considerando-se o elemento limitante nesta área: o fósforo. Alvim resume os resultados assim:

Como conseqüência da queimada da floresta, a fertilidade do solo efetivamente melhora de forma apreciável, em termos da disponibilidade de fósforo, das bases trocáveis, e decréscimo na porcentagem da saturação de alumínio. Após 10 a 11 anos de exploração de pastagens nesses solos, seu nível de fertilidade ainda se conserva bastante elevado em relação aos níveis da floresta primária. (Alvim, 1978)

A parte do fato de que esta comparação não é estritamente verdadeira com respeito ao fósforo $\left(0,69 \mathrm{mg} / 100 \mathrm{~g}\right.$ de $\mathrm{P}_{2} \mathrm{O}_{5}$ sob floresta virgem é mais alto do que o valor $0,46 \mathrm{mg} /$ $100 \mathrm{~g}$ sob pastagem de 10 anos), a questão importante não está em saber se o valor depois de 10 anos é mais alto ou mais baixo do que o valor sob floresta virgem, mas, ao contrário, está em saber se os niveis de fósforo em pastegens mais antigas são suficientes para manter o crescimento adequado do capim e, conseqüentemente, da produção de carne bovina.

O efeito limitante do fósforo no crescimento da pastagem na área foi reconhecido pelos pesquisadores da EMBRAPA nos anos que se sucederam ao estudo original na Be. lém-Brasília (Serrão et al., 1978, 1979) e recomendaram, para remediar, aplicações de $200-300 \mathrm{~kg} / \mathrm{ha}$ de partes iguais de superfosfato e hiperfosfato (Serrão \& Falesi, 1977). Experimentos na área de Paragominas e no Nordeste do Mato Grosso apresentaram respostas bastante positivas quanto à adubação fosfatada (Koster et al., 1977). Os preços extrema. mente altos dos fertilizantes na Amazônia (CrS 6,00 ou US\$ $0,30 / \mathrm{kg}$ pelo superfosfato, em Belém, em 1978) tornam pouco prováveI que os fazendeiros sigam as novas recomen. dações de adubações do governo. A falta de uso de adubos pelos fazendeiros do Estado de

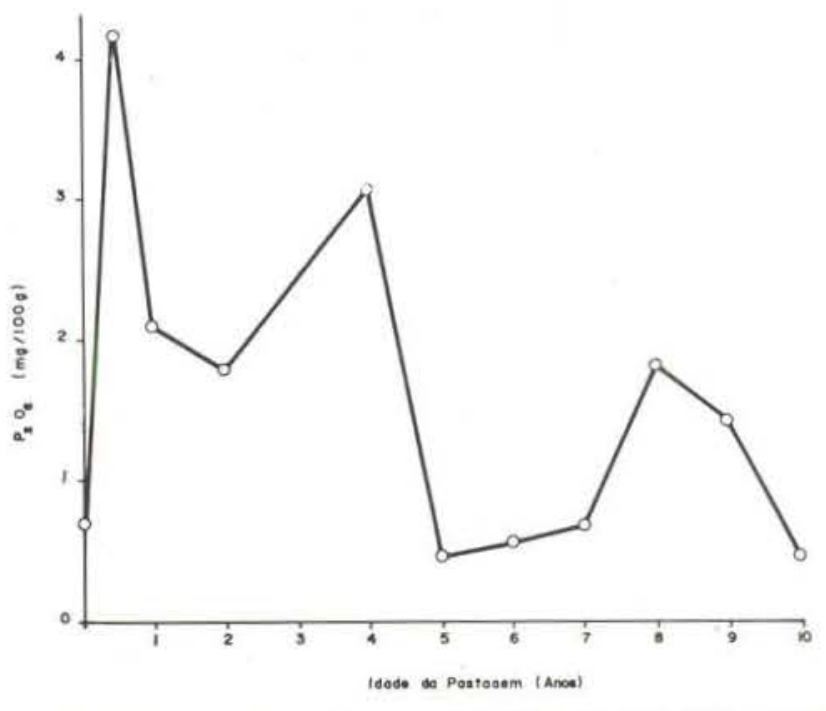

Fig. 4-O fósforo disponivel aumenta dramaticamente com a queimada inicial da floresta derrubada e. então, cai para um nivel mais baixo, depois de cerca de cinco anos. Verificou-se que o fósforo é fator limitante do crescimento das gramíneas em diversas partes da Amazônia, inclusive de Paragominas, na Rodovia Belém-Brasilia. Baixos níveis de fósforo resultam em pobre crescimento da pastagem, sem consideraçāo aos niveis de outros indicadores da fertilidade do solo. Os dados são de Falesi (1976: 42-43).

São Paulo, que estão muito mais próximos das jazidas de fosfato do Brasil (localizados principalmente no Estado de Minas Gerais) do que os da Amazônia, reforça a impressẫo de que as probabilidadies de aceitação da adubação da pastagem pelos fazendeiros da Amazônia são muito pequenas (S. Hecht, Cơmunicação pessoal, 1978). Por exemplo, num levantamento feito em 1977 de 92 fazendas no Nordeste do Pará (a Rodovia Belém-Brasília de Belém até Paragominas e a parte Paraense da Rodovia Belém-São Luiz), apenas uma fazenda $(1,08 \%$ da amostra) tinha usado adubo químico ou orgânico em sua pastagem (Homma et al., 1978).

Quando considerando a possibilidade de pastagens adubados em termos de sustentabilidade, temos que lembrar que o importante neste caso é a economicidade, destas operaçőes. Por exemplo, se alguém fosse disposto a gastar o dinheiro necessário para abastecer pastagem com todas as suas necessidades de vida a qualquer custo, podia até sustentar pastagem na superfície da lua! No caso da Amazônia. precisa-se do cuidado de que o programa 
de incentivos fiscais não tornasse um tipo de desenvolvimento rentável para os beneficiá. rios dos incentivos, o que não seria aconselhável baseado nos seus próprios méritos. Atualmente (junho de 1979), o financiamento do Banco da Amazônia (BASA) para adubação de pastagens em fazendas aprovadas para o programa de incentivos da Superintendência de Desenvolvimento da Amazônia (SUDAM) está feito com empréstimos sem juros (mas com correção monetária), por 2 anos de carência e um prazo de pagamento de 5 anos. No início do programa, os termos eram ainda mais favoráveis, com 7 anos de prazo. Nestes termos, de subsídio governamental, há alguns casos de fazendeiros aproveitando-se da oferta para adubar na área de Paragominas, com resultados muito animadores aos fazendeiros (E.A.S. Serrão, Comunicação pessoal, 1979).

A produção de carne bovina nas pastagens em solos com deficiências de fósforo, como é comum na Amazônia brasileira, é limitada a niveis baixos não só pela produtividade recuzida de matéria seca de pastagem, mas, também, pela necessiaade que tem o gado de consumir mais matéria seca para produzir um dado ganho de peso vivo, face à baixa quali dade nutricional dos capins cultivados nestes solos. Quando os níveis de fósforo baixam no solo, espera-se que o conteúdo nutricional do capim também baixe.

O otimismo geral no Brasil com respeito ao potencial a longo prazo de pecuária na Amazônia é notado por Kleinpenning (1975), que destaca a recomendação de Brücher (1970), que defendeu as fazendas de gado com base na melhoria das raças e em uma pastagem na Colômbia que foi plantada em 1935 e, segundo informações, estava ainda produzindo bem nos últimos anos de 1960. Brücher declara que "as pastagens permanecem produtivas por anos sem a aplicação de fertilizantes", mas sua defesa contém a condição normal de que "métodos modernos" sejam empregados. Tais métodos modernos, além de fertilizantes, podem incluir o plantio de leguminosas intercaladas, que têm aumentado a produção em canteiros experimentais de pastagem sob conáições Amazônicos (Santhirasegaram, 1975). Na Amamazônia peruana, algumas pastagens com leguminosas naturais não fertilizadas têm per- manecido produtivas até por 20 anos (Sanchez, 1976). Tais métodos geralmente não es. tão sendo empregados pelos fazendeiros que vem ocupando rapidamente a Amazônia brasileira.

Grande parte do debate relativo aos solos sob pastagens na Amazônia está voltada à comparação de solos sob gramíneas com solos sob floresta alta, apesar de que isto, muitas vezes, desvia a atenção da questão central, da sustentabilidade de produção bovina; vale a pena observar que a bibliografia sobre o assunto contém muitas declarações contraditórias. A Tabela 1 ilustra o espectro de resultados de estudos sobre comparações da fertilidade do solo superficiai sob pastagens e floresta virgem nos Neotrópicos.

Parsons (1976) fornece um bom sumário dos processos do ciclo de nutrientes sob pastagem. Somente $80 \%$ do nitrogênio, fósforo e potássio consumidos pelo gado é devolvido ao solo em forma de estrume. Entretanto, somente uma fração muito menor dentre estes $80 \%$ será realmente incorporada no solo onde possa ser usada pelo capim, dada a distribuição irregular do excremento. Citando estudos feitos sob "a melhor das condições", em Porto Rico, por Vicente-Chandler (1974), Parsons conclui que somente cerca de metade dos nutrientes das fezes são devolvidos ao solo, o resto é perdido em lixívia e volatilização.

Pode ver-se facilmente nos dados de Parsons como pode dar-se a depleção da fertilidade do solo: somente $50 \%$ dos $80 \%$, ou seja, $40 \%$, dos nutrientes permaneceriam a cada ciclo através do gado. Isto, combinado com perdas adicionais devidas às queimadas e subseqüente lixívia das cinzas, significaria que altas taxas de reabastecimento para os di versos nutrientes teriam que estar operando se não ocorresse depleção.

Infelizmente, Parsons tenta reinterpretar as conclusões de Daubenmire (1972) sobre a questão das mudanças de fertilidade do solo. Parsons escreve (1976) que Daubenmire descobriu pouca mudança na fertilidade .... do solo após 22 anos sob pastagem plantada. A conclusão real de Daubenmire foi: em resumo. pela maioria dos critérios, o nível de fertilidade é mais baixo na savana... (Dauben- 
mire, 1972). Os dados de Daubenmire, alguns dos quais são apresentados na Tabela 1, falam por si mesmos.

Existe alguma evidência de que nem todos os solos tropicais sob pastagem säo melhorados do ponto de vista de fertilidade. Um tal estudo compara solos da Costa Rica, amostra. dos na floresta virgem, numa pastagem de 9 anos e numa pastagem de 15 anos (Krés. 1975). Os dados deste estudo relativos às pastagens são incluídos na Tabela I. Deve notar-se que alguns métodos estatísticos dúbios foram usados na coleta de quatro amostras de cada campo e contando as mesmas como quatro pontos independentes.

Como pode ser observado, a partir dos dados de Krebs na Tabela I, a pastagem de 9 anos tem valores, para todos os nutrientes reiacionados, significativamente mais baixos do que a floresta virgem. Se alguém puder supor que os niveis de nutrientes na pastagem de 15 anos seguiriam o mesmo caminho dos da pastagem de 9 anos, então, depois de 15 anos, somente o carbono e o magnésio possuiram valores significativamente mais baixos do que os valores "virgens"; o restante teria retornado aos níveis não significativamente diferentes dos da floresta virgem. Dos dois eiementos significativamente mais baixos do que os valores virgens, o carbono estaria aumentando enquanto o magnésio estaria diminuindo. O fato de estas amostras virem de somente três locais diferentes pode significar que as diferenças, por exemplo, entre a pastagem de 9 anos e a de 15 anos, não são reâlmente o resultado da queda dos níveis de nutrientes para os valores listados por 9 anos e, depois repercutindo para os listados por 15 anos, mas ao contrário, são o resultado da variação que se encontra entre os campos.

Apesar do problema do tamanho pequeno da amostra, descobertas como aquelas de Krebs acrescentam-se ao peso da evidència indicando que os planejadores brasileiros não devem pressupor que as pastagens tropicais melhoram a fertilidade do solo na ausência de evidência experimental convincente.

Dados de amostras do solo, colhidas em pastagens de idades diferentes nas proximidades e na própria área de colonização de Altamira na Rodovia Transamazônica, sugerem que muitas mudanças nos níveis de nutrientes sob pastagem podem ser melhor consideradas como ajustamentos a curto prazo a novas condições de equilíbrio temporário (Fearnside, 1978). As regressões para predição das m!1danças do nível dos nutrientes durante os pri meircs anos como pastagem fornecem informação adequada para construção de simulações do sistema em computador, uma vez que a forte competição das ervas daninhas invasoras reduz as produções de gramíneas a niveis muito baixos dentro de poucos anos (Fearnside, 1979a, 1979b) .

Além das mudanças na fertilidade do solo, que formam o assunto do atual trabalho, ocorrem muitas outras mudanças com conseqüências na produção bovina, inclusive de compactação do solo (Fearnside, 1978), erosão (Fearnside, 1979c) e invasão de ervas daninhas (Fearnside, 1979a). Pastagens mais antigas na área de Altamira estão quase que completamente invadidas pelas ervas daninhas não comestíveis, como pode ser visto na Figura 5.

\section{A QUESTÃo DA SUSTENTABILIDADE}

O debate vigente no Brasil, relatıvo ao efeito da pastagem de gado sobre a fertilidade do solo, é realmente apenas uma parte da questão mais ampla, ou seja, se as pastagens em promoção na Amazônia serão capazes de resultar em produções sustentáveis, que os planejadores vislumbram.

Talvez tenha sido dada importância demais neste debate à questão da comparaçăo do nível de nutrientes do solo das florestas virgens e das pastagens, isso por três razões: 1) porque a grande maioria dos nutrientes no ecos sistema da floresta estão estocados na vegetação e não no solo, o que torna a comparação isolada dos níveis de nutrientes, do solo em proposição, não representativa, já que os estoques totais de nutrientes da floresta são maiores do que os estoques totais do ecossistema da pastagem; 2) porque a descoberta de que os níveis dos nutrientes do solo são mais altos sob a pastagem do que sob a floresta virgem não induz necessariamente à conclusão de que a pastagem pode fornecer uma produção indefinidamente sustentável, e 3) porque os fazendeiros da Amazônia brasileira podem não estar 


\begin{tabular}{|c|c|c|c|c|c|c|c|c|c|c|c|c|c|c|}
\hline & TABE & $-\mathrm{Cc}$ & Des & esent & is de & tilidade & do Solo & b Pasta & gem e Floresta & Virgem nos & Neotr & icos & & \\
\hline Item & Unidades & $\begin{array}{c}\text { Uso de } \\
\text { Terra }\end{array}$ & $\begin{array}{l}\text { Falesi } \\
\text { (1974: } \\
2.14)\end{array}$ & $\begin{array}{c}\text { Falesi } \\
\text { (1976: } \\
31)\end{array}$ & $\begin{array}{l}\text { Falesi } \\
\text { (1976: } \\
\text { 42) }\end{array}$ & $\begin{array}{c}\text { Falesi } \\
(1976: \\
52)\end{array}$ & $\begin{array}{l}\text { Daub- } \\
\text { enmire } \\
\text { (1972) }\end{array}$ & $\begin{array}{l}\text { Daub- } \\
\text { enmire } \\
(1972)\end{array}$ & $\begin{array}{c}\text { Sombroek } \\
\text { (1966: } \\
\text { 251-252) }\end{array}$ & $\begin{array}{l}\text { Bennema } \\
\text { (1975: } \\
40)\end{array}$ & $\begin{array}{l}\text { Krebs } \\
(1975)\end{array}$ & $\begin{array}{l}\text { Krebs } \\
(1975)\end{array}$ & $\begin{array}{c}\text { Dantas } \\
\text { (1978: } \\
52)\end{array}$ & $\begin{array}{c}\text { Dantas } \\
\text { (1978: } \\
52)\end{array}$ \\
\hline \multirow[t]{2}{*}{$\mathrm{pH}$} & & floresta & 4 & 4,3 & 4,2 & 4,4 & 6,60 & 6,20 & $\begin{array}{l}\text { "levemente } \\
\text { mais alto }\end{array}$ & & $5,41^{\circ}$ & 5,41 & $3,8(4)$ & $3,8(4)$ \\
\hline & & pastagem & 6 & $\hat{n}, 2$ & 6,3 & 6,0 & 6,45 & 6,40 & na floresta" & & $5,09^{\circ}$ & 5,41 & $4,3(4)$ & $5,3(4)$ \\
\hline $\mathrm{Al}+ \pm \pm$ & $(\mathrm{ME} / 100 \mathrm{~g})$ & $\begin{array}{l}\text { floresta } \\
\text { pastagem }\end{array}$ & $\begin{array}{c}\text { presente } \\
0\end{array}$ & $\begin{array}{l}1,09 \\
0,06\end{array}$ & $\begin{array}{l}0,90 \\
0,00\end{array}$ & $\begin{array}{l}1,77 \\
0,00\end{array}$ & $\begin{array}{l}0,12 \\
0,15\end{array}$ & $\begin{array}{l}0,12 \\
0,16\end{array}$ & & & & & & \\
\hline $\mathrm{P}_{2} \mathrm{O}_{5}$ & $(\mathrm{mg} / 100 \mathrm{~g})$ & $\begin{array}{l}\text { floresta } \\
\text { pastagem }\end{array}$ & & 0,53 & 0,46 & 0,23 & & & $\begin{array}{l}\text { niveis } \\
\text { "comparáveis", } \\
\text { fixaçăo "um } \\
\text { pouco menor" } \\
\text { na savana }\end{array}$ & & & & & \\
\hline $\mathrm{N}$ & $(\%)$ & pastagem & $\begin{array}{l}\text { "seme- } \\
\text { Ihante" } \\
\text { em pasta- } \\
\text { gem mais } \\
\text { antiga } \\
\text { (15 anos) }\end{array}$ & $\begin{array}{l}0,09 \\
0,05\end{array}$ & 0,05 & 0,16 & $0,14(1)$ & 0,17 & & & $0,52^{*}$ & 0,52 & 0,17 & 0.17 \\
\hline C & $(\%)$ & $\begin{array}{l}\text { floresta } \\
\text { pastagem }\end{array}$ & & $\begin{array}{l}1,13 \\
0,60\end{array}$ & $\begin{array}{l}0,68 \\
0,54\end{array}$ & $\begin{array}{l}1,62 \\
1,96\end{array}$ & $\begin{array}{l}3,50 \\
2,79\end{array}$ & $\begin{array}{l}2,92 \\
2,65\end{array}$ & $\begin{array}{l}0,5 \text { mais na } \\
\text { floresta }\end{array}$ & $\begin{array}{l}0,54(2) \\
0,35(2)\end{array}$ & $\begin{array}{l}4,45^{\circ} \\
3,55^{\circ}\end{array}$ & $\begin{array}{l}4,45 \\
4,05\end{array}$ & $\begin{array}{l}1,54 \\
1,10\end{array}$ & $\begin{array}{l}1.54 \\
1,00\end{array}$ \\
\hline $\begin{array}{l}\text { Capacidade } \\
\text { de troca }\end{array}$ & $(\mathrm{ME} / 100 \mathrm{~g})$ & floresta & & 6,86 & 4,16 & 10,02 & 24,90 & 23,90 & $\begin{array}{l}\text { "um pouco } \\
\text { mais alto } \\
\text { na floresta" }\end{array}$ & & & & $9,50(4)$ & $4,30(4)$ \\
\hline catiônica & & pastagem & & 4,06 & 2,90 & 8,45 & 25.15 & 29.88 & & & & & $7,10(4)$ & $7,10(4)$ \\
\hline \multirow[t]{2}{*}{ K } & & floresta & $\begin{array}{l}\text { mais } \\
\text { alto na } \\
\text { pastagem }\end{array}$ & $\begin{array}{c}0,08 \\
(\mathrm{ME} / \\
100 \mathrm{~g})\end{array}$ & $\begin{array}{c}0,05 \\
(\mathrm{ME} / \\
100 \mathrm{~g})\end{array}$ & $\begin{array}{c}0,06 \\
(\mathrm{ME} / \\
100 \mathrm{~g})\end{array}$ & $\begin{array}{l}0,57 \\
(\mathrm{ME} / \\
100 \mathrm{~g})\end{array}$ & $\begin{array}{l}0,45 \\
(\mathrm{ME} / \\
100 \mathrm{~g})\end{array}$ & & & $\begin{array}{c}134 \\
(\mathrm{ppm})\end{array}$ & $\begin{array}{c}134 \\
(\mathrm{ppm})\end{array}$ & & \\
\hline & & pastagem & & $\begin{array}{l}0.18 \\
(\mathrm{ME} / \\
100 \mathrm{~g})\end{array}$ & $\begin{array}{l}0,05 \\
(\mathrm{ME} / \\
100 \mathrm{~g})\end{array}$ & $\begin{array}{c}0,22 \\
(\mathrm{ME} / \\
100 \mathrm{~g})\end{array}$ & $\begin{array}{c}0,59 \\
(\mathrm{ME} / \\
100 \mathrm{~g})\end{array}$ & $\begin{array}{l}0,71 \\
(\mathrm{ME} / \\
100 \mathrm{~g})\end{array}$ & & & $\begin{array}{c}99 \\
(\mathrm{ppm})\end{array}$ & $\begin{array}{c}160 \\
(\mathrm{ppm})\end{array}$ & & \\
\hline \multirow[t]{2}{*}{$\mathrm{Ca} \pm t$} & & floresta & $\begin{array}{l}\text { mais } \\
\text { alto na } \\
\text { pasta. }\end{array}$ & $\begin{array}{c}0.31 \\
(\mathrm{ME} / \\
100 \mathrm{~g})\end{array}$ & $\begin{array}{l}0,19 \\
(\mathrm{ME} / \\
100 \mathrm{~g})\end{array}$ & $\begin{array}{c}1,09 \\
(\mathrm{ME} / \\
100 \mathrm{~g})\end{array}$ & $\begin{array}{c}14,75 \\
(\mathrm{ME} / \\
100 \mathrm{~g})\end{array}$ & $\begin{array}{c}12,45 \\
(\mathrm{ME} / \\
100 \mathrm{~g})\end{array}$ & & & $\begin{array}{c}384 \\
(\mathrm{ppm})\end{array}$ & $\begin{array}{c}384 \\
\text { (ppm) }\end{array}$ & & \\
\hline & & pastagem & $\operatorname{gem}(5)$ & $\begin{array}{l}1,24 \\
(\mathrm{ME} / \\
100 \mathrm{~g})\end{array}$ & $\begin{array}{c}1.12 \\
(\mathrm{ME} / \\
100 \mathrm{~g})\end{array}$ & $\begin{array}{c}3,45 \\
(\mathrm{ME} / \\
100 \mathrm{~g})\end{array}$ & $\begin{array}{l}11,95 \\
(\mathrm{ME} / \\
100 \mathrm{~g})\end{array}$ & $\begin{array}{l}13,45 \\
(\mathrm{ME} / \\
100 \mathrm{~g})\end{array}$ & & & $\begin{array}{c}257 \\
(\mathrm{ppm})\end{array}$ & $\begin{array}{c}257 \\
(\mathrm{ppm})\end{array}$ & & \\
\hline
\end{tabular}




\begin{tabular}{|c|c|c|c|c|c|c|c|c|c|c|c|c|c|c|}
\hline Item & Unidades & $\begin{array}{c}\text { Uso de } \\
\text { Terra }\end{array}$ & $\begin{array}{l}\text { Falesi } \\
(1974: \\
2.14)\end{array}$ & $\begin{array}{c}\text { Falesi } \\
\text { (1976: } \\
31)\end{array}$ & $\begin{array}{c}\text { Falesi } \\
\text { (1976: } \\
\text { 42) }\end{array}$ & $\begin{array}{l}\text { Falesi } \\
\text { (1976: } \\
52)\end{array}$ & $\begin{array}{l}\text { Daub- } \\
\text { enmire } \\
(1972)\end{array}$ & $\begin{array}{r}\text { Daub- } \\
\text { enmire } \\
(1972)\end{array}$ & $\begin{array}{c}\text { Sombroek } \\
\text { (1966: } \\
\text { 251-252) }\end{array}$ & $\begin{array}{c}\text { Bennema } \\
\text { (1975: } \\
40)\end{array}$ & $\begin{array}{l}\text { Krebs } \\
(1975)\end{array}$ & $\begin{array}{l}\text { Krebs } \\
\text { (1975) }\end{array}$ & $\begin{array}{c}\text { Dantas } \\
\text { (1978: } \\
52)\end{array}$ & $\begin{array}{c}\text { Dantas } \\
\text { (1978: } \\
52)\end{array}$ \\
\hline$M g \pm \pm$ & (ME/100g) & $\begin{array}{l}\text { floresta } \\
\text { pastagem }\end{array}$ & $\begin{array}{l}\text { mais } \\
\text { alto na } \\
\text { pasta. } \\
\text { gem(5) }\end{array}$ & $\begin{array}{l}0,14 \\
0,58\end{array}$ & 0,21 & 0,38 & 2,98 & 3,08 & & & & & & \\
\hline Idade & (anos) & & até 15 & 11 & 10 & 11 & 22,5 & 22,5 & & & 9 & 15 & $1-5$ & $1-5$ \\
\hline Pluviosidade & $(\mathrm{mm})$ & & 2591 & 1776 & 2591 & 2591 & 1539 & 1539 & & & 4700 & 4700 & 2000 & 2000 \\
\hline Profundidade & $(\mathrm{cm})$ & & $0-20$ & $0-20$ & $0-20$ & $0-20$ & 0,10 & $10-20$ & $\begin{array}{l}\text { "solo da } \\
\text { superfície" }\end{array}$ & 20 & $0-10$ & $0-10$ & $0-20$ & $0-20$ \\
\hline Amostras & (número) & & & & & $\begin{array}{l}\text { "diversas } \\
\text { fazendas" }\end{array}$ & 2 & 2 & $\begin{array}{r}9 \\
\text { (savana) }\end{array}$ & 2 & 8 & 8 & 8 & 8 \\
\hline Comparaçōes & (número) & & & & & & 1 & 1 & 9 & 1 & 1 & 1 & 4 & 4 \\
\hline Local & & & $\begin{array}{l}\text { Parago- } \\
\text { minas \& } \\
\text { Mato } \\
\text { Grosso, } \\
\text { Brasil }\end{array}$ & $\begin{array}{l}\text { Norte } \\
\text { do } \\
\text { Mato } \\
\text { Grosso, } \\
\text { Brasil }\end{array}$ & $\begin{array}{l}\text { Para- } \\
\text { gomi- } \\
\text { nas, } \\
\text { Brasil }\end{array}$ & $\begin{array}{l}\text { Para- } \\
\text { gomi- } \\
\text { nas, } \\
\text { Brasil }\end{array}$ & $\begin{array}{l}\text { Cañas, } \\
\text { Costa } \\
\text { Rica }\end{array}$ & $\begin{array}{l}\text { Cañas, } \\
\text { Costa } \\
\text { Rica }\end{array}$ & $\begin{array}{l}\text { Amapá, } \\
\text { Brasil }\end{array}$ & $\begin{array}{l}\text { Amazô- } \\
\text { nia } \\
\text { Brasi- } \\
\text { leira }\end{array}$ & $\begin{array}{l}\text { San } \\
\text { Carlos, } \\
\text { Costa } \\
\text { Rica }\end{array}$ & $\begin{array}{l}\text { San } \\
\text { Carlos, } \\
\text { Costa } \\
\text { Rica }\end{array}$ & $\begin{array}{l}\text { Itacoa- } \\
\text { tiara, } \\
\text { Brasil }\end{array}$ & $\begin{array}{l}\text { Itacoa- } \\
\text { tiara, } \\
\text { Brasil }\end{array}$ \\
\hline
\end{tabular}

(•) - Diferença significativa relatada $(P<0,05)$.

(1) - Daubenmire (1972) acredita que este valor é alto demais por razöes espúrias.

(2) - Estimado do gráfico a $20 \mathrm{~cm}$ de profundidode (Bennema, 1974: 40).

(3) - Dados paro pastagem para sistema "extensivo" de exploraçăo (o que é mais usado na Amozônia).

(4) - Diferença "significativa" a P $<0,10$ relatada usando procedimento simultâneo de testagem (STP).

(5) $-\mathrm{Ca}++\& \mathrm{Mg} \pm+$ juntos. 
de maneira alguma interessados em uma produção indefinidamente sustentável.

Nos altos níveis do governo, declarações de cbjetivos deservoivimentistas invariavelmente estão voltadas para o ideal de produções sustentáveis. O conjunto de objetivos adotados pelo reunião do Projeto Homem na Biosfera das Nações Unidas no Rio de Janeiro em 1974 ilustra isto (Lawton, 1974). A Superintendência do Desenvolvimento da Amazônia (SUDAM) também tem proclamado isso como um objetivo do seu programa de incentivos para pastagens (SUDAM, 1974). A própria existência do debate sobre os nutrientes do solo fala pelo interesse dos planejadores brasileiros em sustentar futuras produções. Infelizmente, estes objetivos não se aplıcam necessariamente aos fazendeiros individual- mente. O fator chave do ponto de vista do empresário individual é o atrativo relativo aos investimentos alternativos tão logo ele esteja livre para reinvestir em outros locais. Depois de vender uma fazenda que deixa de ser produtiva, mesmo se for vendida por um preço mínimo, um empresário pode investir os lucros ganhos durante o período da sua posse ou em uma fazenda nova em outro local na Amazônia, ou em uma indústria diferente em outro local do Brasil, ou, no caso das corporações multinacionais, em outras partes do mundo. Clark (1976) mostrou a completa racionalidade matemática de indivíduos destruirem os recursos potencialmente renováveis nos casos em que o índice de regeneração forem menores do que o índice de desconto usado no cálculo dos valores monetários atuais de rendimentos futu-

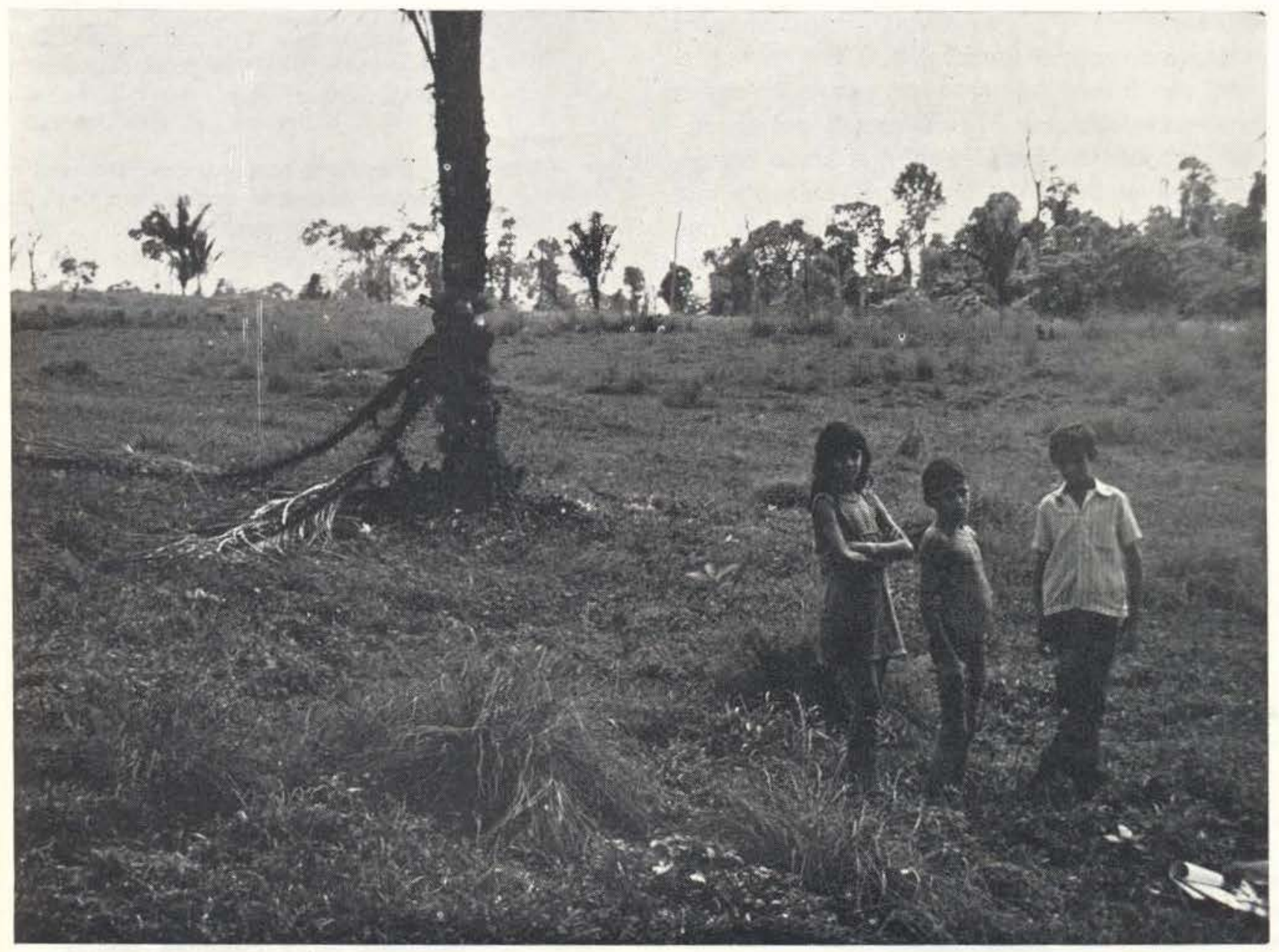

Fig. 5 - Pastagem velha, com baixa produção. Este campo, próximo a Altamira, Pará, foì derrubado pela primeira vez em 1933. Por ocasião desta fotografia ele tinha estado em pastagem por cinco anos, desde o seu mais recente período de pousio em capoeira. Tem estado quase completamente invadido por hortelã (Lamiaciae) nāo comestível.

Os efeitos... 
ros. O caso, muito estudado, da indústria de baleias ilustra isto perfeitamente: as corporações continuam a investir em uma indústria com completo conhecimento de que os índices de exploração vigentes irão levar à destruição das populações de baleias e a um fim da indústria dentro de poucos anos (Clark, 1973). A mesma relação, entre valores atuais e ren. dimentos futuros esperados, beneficia aqueles que estão vendendo fazendas depois de poucos anos de permanência na Rodovia BelémBrasilia ou em Mato Grosso, para reinvestir em novas fazendas na Rodovia Transamazônica. Não existe razão para esperar que estas pessoas não se mudem e reinvestam novamente, como tem sido padrão nas áreas pioneiras em toda o trópico sulamericano (cf. Denevan, 1973) .

Apesar destes problemas, a questão da sustentabilidade é vitalmente importante para o futuro da região Amazônica. Caso os esquemas de desenvolvimento provem não serem sustentáveis, o custo será arcado pelas futuras gerações de brasileiros, que serão obrigados a viver em áreas degradadas depois que a onda prevalescente de empresários se mudar para outros locais. As evidências apreser. tadas sugerem que não se deve esperar, das pastagens da Amazônia, produções sustentáveis.

\section{SUMMARY}

Amazon rainforest is fast being replaced by cattle pastures as investors respond to financial incentives and the lure of new highways. The Brazilian government's encouragement of pasture is linked to claims that pasture improves soil fertility and therefore represents a "rational" means of development in the Amazon. A review if information related to the ongoing debate concerning soil fertility changes under tropical American pastures casts doubt both on the claims of improved fertility for pasture growth, and on the presumption of indefinitely sustainable yields of beef cattle.

\section{BIBLIOGRAFIA}

ALVIM, P. DE T.

1978 - Perspectivas para produção agrícola na região Amazônica. Interciência, 3(4) : 243-251.
BENNEMA, J.

1975 - Soil resources of the tropics with special reference to the well drained soils of the Brazilian Amazon forest region. p. 1-47 In: International Symposium on Ecophysiology of Tropical Crops, Manaus, May 25-30, 1975. Ecophysiology of Tropical Crops. v. 1 .

BRÜCHER, W .

1970 - Rinderhiltung im amazonischem Regenwald. Beiträge zur Geographie der Tropen und Subtropen. Tübinger Geographische Studien Heft, $34: 215-227$.

ClaRK, C.W.

1973 - The economics of overexploitation. Science, $181: 630-634$

1976 - Mathematical Bioeconomics: the Optimal Management of Renewable Resources. Wiley-Interscience, New York. 352 p.

DANTAS, $M$.

1978 - Pastagens da Amazônia Central: Ecologia e Fauna do Solo. Tese de mestrado Instituto Nacional de Pesquisas da Amazônia (INPA), Manaus. $95 \mathrm{p}$.

DAUBENMIRE, $R$.

1972 - Some ecologic consequences of converting forest to savana in northwestern Costa Rica. Tropical Ecology, $13: 31-51$

DENEVAN, W.M

1973 - Development and the imminent demise of the Amazon rain forest. Professional Geo grapher, $25: 130-135$.

DEPARTAMENTO NACIONAL DE PRODUÇÃO MINERAL, PROJETO RADAM.

1974 - Levantamento de Recursos Naturais. Vol. 5. Folha SA.22 Belém. Departamento Nacional de Produção Mineral, Rio de Janeiro.

FALESI, I.C.

1972 - Solos da Rodovia Transamazônica. Instituto de Pesquisa Agropecuária do Norte (IPEAN). Boletim Técnico n.o 55, Belém. $196 \mathrm{p}$.

1974 - O solo na Amazônia e sua relação com a definiçãao de sistemas de produção agrícola. p. 2.1-2.17 In: Empresa Brasileira de Pesquisa Agropecuária (EMBRAPA). Reunião do Grupo Interdisciplinar de Trabalho sobre Diretrizes de Pesquisa Agrícola para a Amazônia (Trópico Úmido), Brasilia, Maio 6-10, 1974, vol. 1. EMBRAPA, Brasilia.

1976 - Ecossistema de Pastagem Cultivada na Amazônia Brasileira. Boletim Técnico do Centro de Pesquisa Agropecuária do Trópico Úmido (CPATU) n.o 1, Belém. 193 p. 
FEARNSIDE, P.M.

1978 - Estimation of Carrying Capacity for Human Populations in a part of the Transamazon Highway Colonization Area of Brasil. Tese de Ph.D., University Microfilms, Ann Arbor. 624 p.

1979a - Previsão da produção bovina na Transamazônica do Brasil. Acta Amazonica, 9(4) : $689-700$.

1979b - A Simulação da Capacidade de Suporte para Populações Humanas nos Trópicos Úmidos: Programa de Computador e Documentação. (mimeografado).

1979 c - A previsão de perdas de solo por erosâo sob vários usos de terra na área de colonização da Rodovia Transamazônica do Bra. sil. Acta Amazonica (no prelo).

1980 - The effects of cattle pastures on soils of the Brazilian Amazon: consequences for beef production sustainability. Tropical Ecology. (aceito para publicação).

Homma, A.O.; SÁ, F.T.; Nascimento, C.N.B. DO; Moura Carvalho, L.O.D. DE; Mello Filho, B.M.; Moretra, E.D. \& Teixeira, R.N.G.

1978 - Estudo das características e análises de alguns indicadores técnicos e econômicos da pecuária no Nordeste Paraense. EMBRAPA - CPATU Comunicado Técnico (13) $: 1-40$.

IPEAN

1974 - Solos da Rodovia Transamazônica; trecho Itaituba-Rio Branco; relatório preliminar. IPEAN, Belém. 53 p.

Kass, D.C.L. \& Lapes, A.M.

1972 - Variedades de arroz para o cultivo de sequeiro no Estado do Pará. Instituto de Pesquisa Agropecuária do Norte (IPEAN) Comunicado (15) : 1-7.

KLEINPENNING, J.M.G.

1975 - The Integration and Colonization of the Brazilian Portion of the Amazon Basin. Institute of Geography and Planning. Nijmegan, Holland. $177 \mathrm{p}$.

Koster, H.W.; Khan, E.J.A. \& Bosshart, R.P.

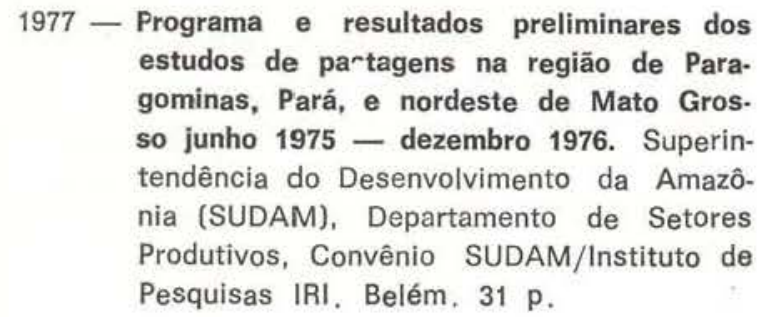

Os efeitos...
KREBS, J.E.

1975 - A comparison of soils under agriculture and forests in San Carlos, Costa Rica. p. 281-390 In: Golley, F.B. \& Medina, E. (eds.) Tropical Ecological Systems Trends in Terrestrial and Aquatic Research. Springer-Verlag, New York. 398 p.

LAWTON, R.M

1974 - Notes on the post MAB project 1 working group tour of Brazil, 16-19 February 1974. Land and Resources Division, Overseas Development Administration, London. (mimeografado) $10 \mathrm{p}$.

PARSONS, J.J.

1976 - Forest to pasture: development or destruction. Revista de Biologia Tropical (Universidade de Costa Rica), 24 (supl. 1) : 121-138.

SANCHEZ, P.A.

:976 - Properties and Management of Soils in the Tropics. John Wiley and Sons, New York. $618 p$.

SANTHIRASEgaraM, K.

1975 - Management of legume pastures in a tropical rainforest ecosystem of Peru. p. 434-452 In: Bornemisza, E. \& Alvarado, A. (eds.) Soil Management in Tropical America: Proceedings of a Seminar held at CIAT, Cali, Colombia February 10-14, 1974. North Carolina State University Soil Science Department, Raleigh, North Carolina. 565 p.

Serrâo, E.A.S.; Cruz, E. de S.; Simões Neto, M.; Sousa, G.F. te; Bastos, J.B. \& Guimaräes, M.C. De F.

1971 - Fesposta de três gramíneas forrageiras (Brachiaria decumbens Stapf., Brachiaria ruziziensis Germain et Everard e Pennisetum purpureum Schum.) a elementos fertilizantes em latossolo amarelo textura média. Instituto de Pesquisa Agropecuária do Norte (IPEAN) Série: Fertilidade do Solo, $1(2): 38 \mathrm{p}$.

Serrão, E.A.S. \& Falesi, I.C.

1977 - Pastagens do Trópico Úmido Brasileiro. Centro de Pesquisa Agropecuária do Trópico Úmido (CPATU), Belém. $63 \mathrm{p}$.

Serrão, E.A.S.; Falesi, I.C.; Veiga, J.B. DA \& NETO, J.F.T

1978 - Frodutividade de Pastagens Cultivadas em Solos de Baixa Fertilidade das Áreas de Floresta do Trópico Úmido Brasileiro. Empresa Brasileira de Pesquisa Agropecuária (EMBRAPA) - Centro de Pesquisa Agropecuária do Trópico Úmido (CPATU), Belém, $73 \mathrm{p}$. 
1979 - Productivity of cultivated pastures on low fertility soils in the Amazon of Brazil. p. 195-225 In: Sanchez, P.A. \& Tergas, L.E. (eds.) Pasture Production in Acid Soils of the Tropics, (Proceedings of a Seminar held at CIAT, Cali, Colombia, 17-21 April 1978) Centro Internacional de Agricultura Tropical (CIAT), Cali, Colombia, Beef Program Series O3EG-5. $488 p$.

SOMBRoeK, W.G.

1966 - Amazon Soils: a Reconnaisance of the Soils of the Brazilian Amazon Region. Center for Agricultural Publications and Documentation, Wageningen, Holland. $292 \mathrm{p}$

\section{SUDAM}

1972 - Isto é Amazônia. SUDAM, Belém, 48 p,

1974 - Consideraçōes sobre a Pecuária na Amazônia (Documento preliminar apresentado ao IV SERAM-AGROPECUARIA - São Paulo - SP. 04 a 08/02/74). SUDAM, São Paulo. $48 \mathrm{p}$.

VICENTE-CHANDLER, J.

1974 - Intensive grassland management in the humid tropics of Puerto Rico. Agricultural Experiment Station, Rio Piedras, Puerto Rico, Bulletin (233).

(Aceito para publicação em 06/07/79) 